\title{
Two-Row Wampum Reimagined: Understanding the Hybrid Digital Lives of Contemporary Kanien'kehá:ka Youth
}

\author{
CURRAN KATSI'SORÓKWAS JACOBS \\ McGill University, Canada
}

\begin{abstract}
This article explores the digital life of one Indigenous youth and her experience with multiliteracies. The piece emphasizes the hybrid identity of contemporary Indigenous youth who not only reconcile traditional and contemporary identities, but also participate actively in several digital communities and life worlds. Through a participatory action research approach, listening to the digital experiences of youth can have fundamental impacts for creating more socially just pedagogical practices for multimodal multiliteracies.
\end{abstract}

KEYWORDS multiliteracies; Indigenous identity; digital technology; hybridity

\section{Introduction}

The two-row wampum, an agreement or document - although not in the western, literary sense - was created by the Haudenosaunee during the early days of colonization, ${ }^{1}$ when Europeans came to Turtle Island and decided that this was to be their new home. The Haudenosaunee people were welcoming of their new neighbors to the point of proposing the agreement of the tworow wampum to ensure that peace be maintained in this new reality. Depicted on a belt were two rows, one representative of the Haudenosaunee canoe and the other of a European ship, the lines ran parallel to one another from beginning to end. The agreement was to be that both ship and canoe, Europeans and Haudenosaunee, would share the river and each stay in their boats. As the story goes, as my father tells it, the Europeans ignored the requests of their neighbors, and there were multiple collisions within that river (Calvin Jacobs, personal communication). Colonial history has turned

\footnotetext{
${ }^{1}$ The Haudenosaunee or Iroquois Confederacy is made up of six nations: Cayuga, Onondaga, Seneca, Oneida, Mohawk and Tuscarora.
} 
the two-row wampum into just another story we tell; a remnant of ancient literacies that pre-date the contemporary world. However, for the Haudenosaunee people, it is a living narrative, passed down through the generations, guiding the lives of the people who are now faced with an alternate existence to what might have played out if the European counterparts maintained their end of the bargain.

Fast forward to the present. A document without words, a story my father tells me, a history that pervades the identity of Kanien'kehá:ka (Mohawk) people, the two-row wampum, I admit, is something that I have reclaimed in my own understandings of the world to describe an emergent, contemporary phenomenon: the hybridity of Indigenous identities and literacy practices in contemporary society. As an educator, I use the two-row wampum to describe my experience and that of my students, Kanien'kehá:ka youth in the greater Canadian society. Now that colonialism has defined space for us both in the ships and in the canoes, our balancing act, day in and day out, is to ride that river with one foot firmly planted in each boat. This act is tough, but it is what we do in pursuit of the decolonial project: our lives. The experiences of the youth participants I had the chance to learn from during the inquiry leading to this paper, each achieved this balance in their own ways. Maren, the youth I spent most of my time with, represents this balancing act both in her digital communities and in real life. She is a prime example of the reimagined two-row wampum.

\section{Positioning Indigenous Knowledge}

It is important to acknowledge that my own worldview and perceptions both personally and academically are embedded in the traditional teachings that I have had access to my whole life. As a Kanien'kehá:ka person and member of my community, it is essential to recognize where traditional teachings and stories come from. Marie Battiste (2005) discusses that the transmission of cultural knowledge through the generations is shared "through modelling, practice and animation, rather than the written word" (p. 2). In discussing her attempt at a literature review of Indigenous knowledge, she remarks on how the practice is misidentified as knowledge for most Indigenous cultures is not literature but rather "embedded in the cumulative experiences and teachings of Indigenous peoples" (Battiste, 2005, p. 2). As I explore and expand upon concepts such as the two-row wampum, I acknowledge that this knowledge is not mine to claim alone, but is a part of my upbringing and my collective identity as a Kanien'kehá:ka person. As I weave this traditional knowledge with new understandings and theory, I too practice navigating space with a foot in each vessel. I hope to maintain the integrity of my cultural upbringing and community by acknowledging people like my father who are transmitters of knowledge; knowledge that is not confined to one person's thoughts and understandings, but is a part of the collective identity and world view of a 
whole nation of people. A levelling of the playing field, in a way, is part of the decolonizing process that is discussed throughout this piece; positioning Indigenous knowledge on equal footing with Western thought is not unlike the necessity for discussing Indigenous literacies as a piece of the multiliteraties conversation.

\section{Two-Row Wampum and Identity}

I use the image of the two-row wampum for several reasons. I believe it is essential as the basis of my writing this piece is to discuss multiliteracies as they are emergent in classrooms and society at large. It can be challenging, even as an Indigenous academic to include culturally relevant literacies as a part of the larger discourse of multiliteracies. However, reflecting the practices of youth like Maren is a reminder that what she is creating and engaging with on a daily basis is the infusion of her identities. The literacy practices that she engages in are created by the colonial history and are influenced and infused with the understandings from each respective community and history she belongs to.

The two-row wampum's origin, a belt, is an example of a non-western epistemology at work. This reinterpretation of its significance acts as a marker for the transformative nature of literacy over time and space (De Souza, 2015). But most importantly, it signifies a piece of the multiliteracies conversation that is underrepresented after 20 years: Indigenous perspectives and experiences.

The initial shift from a single, autonomous view of literacy to an ideological view of multiliteracies has been crucial in unpacking the experience of youth today (Alvermann, 2009). To understand the literacy practices of contemporary digital youth, as suggested by the New London Group (1996), the education system needed revitalized teaching practices to accommodate and consider diverse experiences and types of literacy. Literacy, previously understood as reading and writing, transforms as new media develops; contemporary literacy practices encompass diverse skills and knowledge acquired through engagement with media and the communities that embrace them. Curriculum and pedagogy should reflect the various cultures of students while creating fair and inclusive schools (Lavoie, Sarkar, Mark, \& Jeniss, 2008). Acceptance and integration of Indigenous literacies, particularly, is necessary in the transformation of schools. Essentially, the education system needs to undergo a complete decolonization.

Decolonization means reconciling diverse histories, and understanding that there are multiple perspectives from these histories that must be accepted to move forward (Jacobs, 2016). I assert that to move deeper into the decolonial project of progress and socially just practices, particularly for the case of Quebec and Canada, the starting point is with youth. The contemporary concern for literacy developments rest on the daily lives of Indigenous youth 
who are models of hybridity in practice and in identity. While the education system looks to create learning that is relevant and essential for the $21^{\text {st }}$ century, it is time move away from prescriptive, researcher-driven inquiries (Mirra, Filipiak, \& Garcia, 2015). The next move, particularly for the benefit of Kanien'kehá:ka youth, is to hear from the youth themselves. Creating spaces for reflection of digital self, cultural self and what this means in youths' communities should be the guides for multiliteracy progression in the $21^{\text {st }}$ century. When teachers are exposed to the real life literacy practices of their students, they are better equipped to create meaningful literacy learning situations (Perry, 2012). Everything that was suggested about societal shifts in youth literacy has already been happening in the wake of colonialism, and it starts with listening to the experiences of resilient Indigenous youth who just want to participate in the world (Kovach, 2005).

The New London Group (1996) emphasized in their work the hybridity of practices: the combination of literacies and contexts is the future. Indigenous youth are models of hybridity in their daily-lived experiences as they are silently negotiating two (or more, in some cases) worlds constantly. Although there are instances of explicit cultural infusions throughout the work and experience of Indigenous individuals who are what Ginsburg (2008) considers cultural activists, Maren's work, without being explicitly representative of her Kanien'kehá:ka identity, is emergent from her hybrid identity.

\section{Research Background}

This article follows a youth participatory action research project that took place in an urban Kanien'kehá:ka community. The intentions of the project were to engage youth in one of the community's teen centres in discussing their digital identities and practices, reflecting upon their experiences with digital media and technology in school, and to create digital stories for their teachers from their community school that demonstrate their experiences and interests in the digital worlds. The participants of this project ranged from 13 to 17 years of age and comprised youth who both attended the local high school and youth who attended school in both private and public sectors in surrounding communities. The teen centre is a designated program created by the community with the mandate of developing youth in several capacities to prepare them for the world.

Maren, 13 years old, attends a private school in a neighbouring community. She is a member of the teen centre who actively participates in the programming, and is equal parts outspoken and informative. While her formal educational experience has not fostered her literacy development effectively, it is her own drive, interests and sense of belonging in her online communities of digital art that have motivated her to be the best at what she does; that is, create, co-create and interact with others in digital art platforms 
and communities. Her understanding of and engagement with the digital art community is her raison d'etre, and when teased out further, is one of the building blocks for informing socially just changes to literacy practices.

The youth, including Maren, engaged in six two-hour sessions with the research team to discuss, plan and create their digital stories. Over the course of the sessions, Maren and I engaged in informal working sessions where we discussed her digital practices, perceptions of digital identity, and school. It was through these same six sessions that I mentored her through the creation of a speed paint video, which she decided was representative of her digital skills. The organic process dictated the actions of each session with the overarching guiding question of what each youth thought teachers should know about their digital lives.

This project is of particular interest and importance for me as an educator, researcher and community member. In its earlier manifestations, the teen centre was a space where I spent my formative years, and I can attest to the significance of such a structure for the lives of other Kanien'kehá:ka who are growing up in this new and complex world. As an educator in this community, I experienced the shifts occurring in the local education system to move towards a $21^{\text {st }}$ century curriculum that is representative of contemporary educational concerns and traditional knowledge. A major component of this is the integration of technology into the curriculum, and so this project is another form of reconciliation for youth to present their aligned concerns with the educational system.

Engagement with youth like Maren may catalyze the necessary transformations of educational institutions and literacy as imagined by the New London Group. Learning alongside youth about their individual practices offers opportunities to experience and unpack how the reimagined two-row wampum might manifest differently amongst individuals. Youth driven action-research is a powerful tool in this instance; the knowledge generated in these scenarios allows for growth amongst participant and researcher, youth and adult.

\section{Theoretical Framework}

Hybridity is not a new concept. The New London Group (1996) identified the multiple life worlds that youth occupy, and described the complex relationships between each one. The more diverse worlds youth participate in, the greater likelihood of emergent relationships and new literacies. In Indigenous contexts, hybridity by name may be viewed as contentious or radical as there is a desire for authenticity (De Souza, 2015). The historical and continued depreciation of Indigenous literacies in dominant discourses, alongside fear of assimilation, can make it particularly repugnant to claim contemporary Indigenous identity as hybrid. And yet, as De Souza (2015) asserts, Indigenous identities and literacies are in constant transition, as a 
reconciliation dance is performed between dominant and Indigenous cultures. A contemporary Indigenous digital youth, in this case, is the amalgamation of all of the spaces they occupy, and it is this hybridity that delineates their interests, literacies and identity.

Multimodality is another concept that is particularly Indigenous, and yet was prioritized by the New London Group (1996) in their pursuit to redefine literacies. While Indigenous literacies are not limited to visual representations, imagery is a major form of communication in many cultures (De Souza, 2015). An image - whether drawn or crafted with other material might connote narrative or historical significance. Art is the opportunity to present messages without oral or written language, and in an early European understanding, meaning in representation was determined through interpretation "of the rational mind" (De Souza, 2015, p. 163). For many Indigenous contexts, however, representation was less about interpretation, and rooted deeper in culture and community significance. A particular image can only be impactful if it is something known and shared - if it connotes history and cultural knowledge. In its time, the two-row wampum belt was a visual representation of concept, agreement and history that resonates for Kanien'kehá:ka people both of the past and of today. This is a valued literacy for community that is not prioritized in greater western contexts. It is a valued literacy that is prioritized for educational progression, as it is a proponent of contemporary Indigenous literacies.

Digital media are multimodal and flexible. They make up a large proportion of contemporary literacies, as they encompass the primary literacies of reading and writing, and extend well beyond to visual and other sorts. Digital media is particularly vital in the discussion of contemporary Indigenous literacies as its visual and aural nature are aligned with cultural epistemologies (Mills, Davis-Warra, Sewell, \& Anderson, 2016). Contemporary Indigenous people are continuing the hybrid world with different projects, in various platforms and in development of diverse media (Ginsburg, 2008). As Kral (2010) asserts for the case of Australia, "Indigenous youth are now firmly part of digital culture and are playing an increasingly salient role as the mediators of new media" (p. 1). In Canadian contexts, Indigenous youth are acting as creators and ambassadors in digital communities and doing so autonomously, driven by interest.

In some of these instances, youth are acting as agents of cultural activism (Ginsburg, 2008), explicitly creating content for the sake of revitalizing relationships to culture and land. These moments of cultural activism are about appropriating western literacies and practices, and infusing them with the cultural undertones of Indigenous knowledge and world views. This is an explicit act of hybridization that exists in the practices of youth and other Indigenous peoples. However, the nature of hybridity that emerges in nonexplicit digital creations might also be seen as a form of cultural activism. Indigenous youth who create mash up videos that are not explicitly about Indigenous identity or culture tell a different side of their story. These types 
of creations are culturally activist because they defy possible notions that being Indigenous means something specific; being Indigenous means being hybrid. Hybridity means participating in the world and occupying multiple spaces.

One of the realities about youth, regardless of their formal education, is that they are literate. While school focuses on reading and writing as a primary form of literacy, youth are engaging in activities outside of school where they build additional skills and literacies. Interest drives youth culture, and the development of platforms, community and various digital literacies, which emerge simply by youth pursuing something valued (Alvermann, 2009). Those who are not particularly academic, or who lack in reading and writing abilities, are still capable of participating in their digital communities (Alvermann, 2009). The multimodality of literacies in these capacities not only allows space for youth to express themselves in ways other than writing, but also even encourages them to develop writing skills as a means of not being left out. Youth are driven by their own reasons for literacy and are unimpressed with the supposed necessity of academic literacy. On the other end of the spectrum, Alvermann (2009) asserts that the multitasking nature of some students in school occurs because they have already mastered their expected literacy developments and are bored. These students are the ones who seek meaningful work, and might view schoolwork as mere obstacle. They are the busy bodies, scrolling the websites they are not supposed to and doodling in their agendas because perfecting their shading technique is far more valuable than close reading and sentence structure.

The alternatives forms of literacy to reading and writing which youth are partaking can seem challenging to grasp when we are unsure how to describe and discuss them. An understanding of culture or literacy can only be explained with the language that one has, and there can be blocks that go up when presented with something new and different (De Souza, 2015). There can be an aversion to multimodal multiliteracies with individual inexperience, but this can be remedied by the development of what De Souza (2015) calls critical literacy. This is a concept that explores the how and why of a person's understanding. That is, individual understanding is a symptom of position, and to be self-aware of your shortcomings and point of entry is to be critically literate. Critical literacy in education is essential, particularly with the necessary shift in transformed practice of pedagogy (New London Group, 1996), because it is not only expanding the canon of literacy but also carving out space for youth-driven meaning making and effective global citizenship. Teachers and schools need to be responsible for listening to their obviously literate youth and provide models for them on how to practice critical literacy with respect to their own community participation. 


\section{Two-Row Wampum Reimagined through Maren's Multiliteracies}

Maren occupies several spaces, creates and conveys her thoughts through a variety of media, and as a result, navigates her water balancing between boats with ease. She occupies multiple lifeworlds simultaneously (New London Group, 1996). The traces of her infused multiliteracies manifest in her engagement with both physical and digital art and in her preference for visual representation and oral communication over writing. This section of the article will present Maren's narrative and present the two major components of this narrative that demonstrate her simultaneous adherence to both traditional and contemporary identities. Maren's experience is a model of cultural activism and $21^{\text {st }}$ century global citizenship.

\section{Maren's Practices}

When I first met Maren, she was sitting at a table in the teen centre she frequents, listening to music on a CD player. This was an obvious conversation starter, as she was using technology that many other youth in her own generation might never have heard of. My interest in her reasons for still using a CD player started the conversation, which led deeper into her experiences with technology and digital media. Immediately following her explanation of her out-dated CD collection she turned my attention to her notebook that was filled with drawings. Maren is a self-taught artist who specializes in character drawings and has a repertoire of drawings completed both with traditional pen and paper and with digital media.

Maren taught herself to draw by using a drawing dictionary that she read and followed along with, picking up technique and developing her own sense of style. She posts her drawings primarily on Deviant Art, a website devoted to the creation and sharing of artwork. In Deviant Art, she participates in the community by posting her creations and "watching" others do the same. There is a camaraderie developed in the interactions between users of this platform, as well as an active practice of adoption and sale of characters. Maren specifically creates some of her drawings for adoption, so that other users can take ownership over her drawings and use them for a variety of purposes. She also adopts or purchases characters from other users using cryptocurrency, and adds them to her collection of drawings.

Some of the drawings are pictures of characters she created in her notebook, and others are digital creations she made using digital drawing platforms. One of the platforms she spoke extensively about using was Aggie.io. This platform is a collaborative painting application that allows users to produce pixel art using multiple layers, while doubling as a place for artists to work together on drawings through the internet. She has tried many of the free applications available, and for the creation that she made during our time, she used a different platform called Frame Cast, which has a similar 
function to Aggie.io (see Figure 1). Along with the 2-D characters she creates in these platforms, Maren has also begun to experiment with small animations, creating moving GIF characters. She posts those on her Deviant Art account as well, and put one up for adoption by a prominent user in the Deviant Art world. When Maren described how exciting it was for this user to choose her character as her avatar, it was clear that this user had made an impact on Maren's experience in the community.

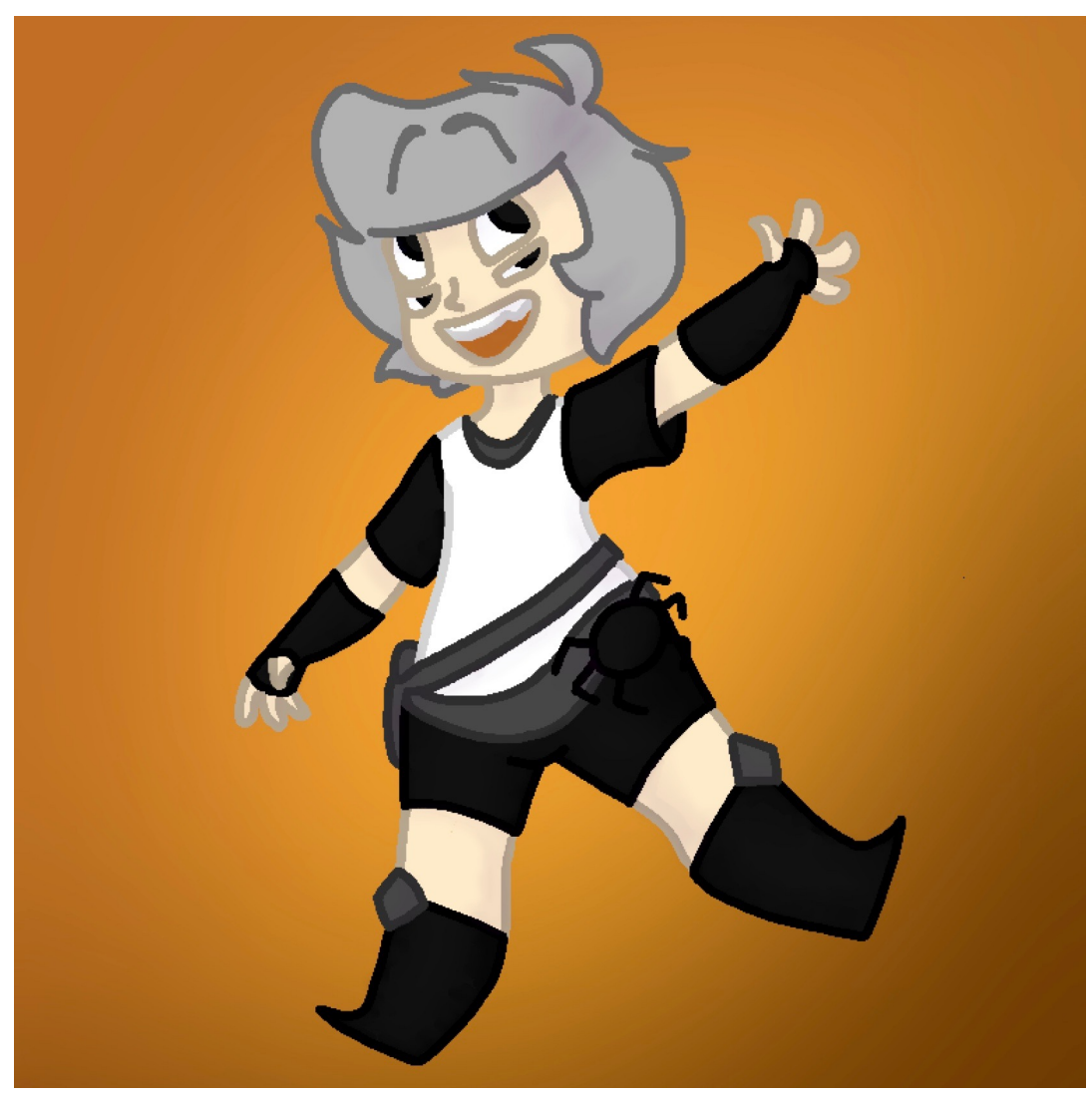

Figure 1. Character drawing created by Maren using the Frame Cast application.

Maren uses Instagram and YouTube to display her art and as a way to find and follow other artists, music and other forms of popular culture (like memes). She also has a server in the Discord application, which is a prominent tool for online gaming and communities. In this platform, she engages directly with other people who share her interests by creating thematic threads to organize and maintain conversations. She engages in conversation with her friends through all of the platforms she uses. She has 
developed relationships with people she has met in real life and online, and engages daily with her drawing.

Maren discussed her of understanding of the social constructs at play across communities. She occupies multiple spaces simultaneously, and is aware of the hierarchies in each place. On a digital level, social status is gained by the number of watchers one has in Deviant Art: the more you interact with others, produce new pieces and develop your skills, the more mobility and popularity you have. An example of this is the user who adopted Maren's animated character. This user is prominent in both the Deviant Art and YouTube communities, and has developed skills to create full-length animated videos with characters that are digitally drawn. Maren looks up to this user, admires the work that they create and aspires to develop her own skills to match those of this user. Maren discusses not only the implicit camaraderie but also emphasizes the explicit encouragement and sense of community that exists among users in her platforms. Almost everyone she encounters is supportive and wants to help one another to develop their drawing skills. Maren acknowledges that the dynamics of her online worlds also exist in the real world.

As noted by the New London Group (1996), what Maren is describing in her experience with the online art community is the shift in hierarchy of command to one of "postFordism" (p. 65); where workplace, or in this case community dynamics and hierarchy, are created within community rather than imposed upon community. Mentorship is the key to mobility in this space and as Maren engages with more users, she learns how to access this mobility.

\section{Balancing Physical and Digital Art}

The progression of Maren's art from using pencil and paper to engaging in digital platforms is reflective of the transformative nature of digital engagement. Drawings take on a new life when they are posted to online forums, as they become part of the discourse in the communities with which they are shared. Maren's move from drawing on paper to engaging with new platforms and creating digitally manifests the transformation and development of her literacies driven by interest and necessity (Alvermann 2009). Simultaneously, Maren is developing skills that are valued (or emerging as valuable) in the workplace. Similar to the changes in hierarchy, a shift is being made in the communication of workspaces to reflect a more informal and digital format (New London Group 1996). Her interest comes with the desire to create new drawings, and to improve skills, while the learning and development of skill involved (i.e., navigating new applications or layering colours and line work) evolves from the interest to be a part of the community and create at the same level as others. Maren is simultaneously participating in and extending discourse with her contributions to the digital 
art world. She is also obtaining skills and developing literacies independently that might support her future career (whatever that may be) by engaging with these new ways of communicating.

The art that Maren creates is not explicitly representative of her Indigenous identity. Throughout our conversations, she never mentioned the fact that she was Indigenous; she did not make any connections of this part of her identity to her artwork. This exclusion is essential despite any of the parallels and assumptions that might be made between traditional and cultural literacies and Maren's current practices. The only certainty about the indigeneity of her artwork is that she identifies as Kanien'kehá:ka. This is crucial in the discussion of her hybrid practices and identities. She is creating art and participating in digital worlds and is also Indigenous. These facts are distinct and at the same time are parts of the whole: Maren. Her cultural activism (Ginsburg, 2008) is neither implicit nor explicit in her art; she is a cultural activist by occupying space in multiple lifeworlds simultaneously.

\section{Trading in Writing for Showing}

Maren's digital identity and literacy practices are diverse. One of the primary things she brings up is that she is not interested in writing, and is far more comfortable with conveying meaning through visual representation. She described a character whose name and colour choices were based on a sunset. She acknowledged that this particular manifestation of a sunset was her perception and realized that other people and creatures might see the colors differently. However, she would rather present messages in a drawing than in writing. Several things are happening when she describes her decisions for the character above. Maren is first engaging in the perpetuation of artistic styles, symbols, archetypes without prompt. She is engaging in knowledge creation independent of her education, which can be perceived as far more valuable than simply writing about something. She is also using conventions of her craft and drawing literacy to convey specific meaning that she knows other artists who engage in the same kind of work will understand. She is communicating in a sophisticated, non-verbal, non-written fashion that defies the expectations and importance of writing because this literacy allows her to participate in her community. She is also applying conventions of writing to visual representation when she talks about symbolism, which aligns with the New London Groups' (1996) assertion that "text is also related to the visual" (p. 64). Not only are new forms of communication being created with the introduction of new media, these new literacies also impact the ways in which language is used (New London Group, 1996). Although Maren explicitly rejects writing as her preferred means of communicating, she is using language and literary conventions to discuss her work; this is indicative of her autonomous education, which takes place as she navigates her digital worlds. 
Maren's experience is particularly fruitful to the conversation of literacy practices because of her cultural activism. Her development of digital art started from her understandings of visual art as something you create with pen and paper, and yet, her introduction to the digital world and the platforms provided allowed for her self-discovery of a new literacy: pixel art. Everything that she creates is created in tension with her multiple lifeworlds, as she draws on inspiration from her surroundings (community, family, etc.) and what she is exposed to online. She is unapologetically adding to the pixel art discourses, and occupying space as a Kanien'kehá:ka person in different communities. This is her hybridity. Her ability to occupy space seamlessly in various communities, including her Indigenous community is what maintains her balance with a foot in each boat through the water.

\section{Implications for Decolonizing Theories of Multiliteracies}

Reconciling identity day in and day out is a task that is done so quietly, and sometimes without even knowing it. Maren is representative of hybridity in action as she occupies multiple spaces, and participates in literacy practices that are representative of all of these spaces that she occupies. Her willingness to share this story with me speaks of the untapped potential that is brewing within. Moreover, Maren's engagement in these digital communities has demonstrated that although her creations are not explicitly Indigenous or representative of this part of her identity, her participation is a blend of the life worlds she occupies. She is a living incarnation of the contemporary tworow wampum. The authenticity of her Indigenous identity while engaging in other communities will always be maintained because contemporary Indigenous identity is about balancing.

What her story seeks to catalyze is the integration of multimodal, multiliteracies in the education system that are not prescriptive of what curriculum writers perceive as important for development and success, but rather which are youth-driven and rooted in diverse literacies. Uprooting the ways in which we prioritize literacies will lead to the hybridity that The New London Group presented, and that exists in the lives of each Kanien'kehá:ka youth.

There is a responsibility now for students and educators to take on the role of change makers who have power (New London Group, 1996). Teachers need to begin teaching students skills that are reflective of the new workplaces as well as fostering student capacity to be vocal, critical and to share their already abundant knowledge of their multiple lifeworlds and the skills that come with them (New London Group, 1996).

The need for inclusive classrooms and pedagogy is key. Understanding the hybridity of individuals is necessary for developing a culture of hybridity in classroom and learning. While youth are continuing to partake in different communities and creating new forms of literacy in their daily lives, it is 
crucial that the education they receive emphasize these individual differences. Creating the space for youth to decide what platforms and skills are necessary for their own interest and self-development is crucial, but more importantly, the openness to multimodal practices will add to the environment.

More importantly, youth need to take on their more than deserved role as knowledge creators. Simply asking youth what they do and how they do it can lead to deeper conversations into how they navigate time and space and what they perceive of as essential in the changing world. Asking them to teach teachers and other adults is a far more fruitful exercise, because ultimately they are much better at keeping up with the times. In these dialogues and collaborations, not only are student and teacher creating dialogue around already existing practices, they are creating new practices and relationships; they are creating knowledge together.

Decolonization began as a land-based pursuit, with the intention of actually dismantling colonial impacts on the land and the original people who occupy those lands. While contemporary colonized countries are well past the point of decolonizing land per se, there has been a shift beyond physical reclamation and into emotional, mental and social revitalization. Beyond this, with the development of digital platforms, the pursuit of decolonization has also moved into occupying space and contributing to the discourses in ways that might not have been intended. While youth like Maren are participating extensively in decolonizing digital spaces and dismantling stereotypes of what contemporary indigeneity entails, it is time now for educational institutions to hold up their end of the deal. But how do they do this?

Rather than maintaining focus on the inclusion or proper representation of Indigenous literacies in the educational infrastructure, the focus must shift to the Indigenous youth who are living this hybridity, to ask them to guide us through what Indigenous literacies might look like in this ever changing world. Creating forums for their voices to tell the stories of navigating digital space as an Indigenous person is the next step necessary for creating socially just pedagogy and ensuring that the multimodal multiliteracies that youth are engaging with in their formal education are not only culturally relevant but useful in the pursuit of leading successful and meaningful lives. Collaboration is how the best ideas come to fruition. Teachers and schools need to develop their own literacy: a critical literacy of exercising listening and learning from their cultural location, and engage in the challenging work of making sense of someone else's experiences (De Souza, 2015). This is the collaborative learning for the future.

\section{Acknowledgements}

I wish to acknowledge the funding to this project provided by the NCTE Research Foundation Grant. I also wish to acknowledge the youth in my community who continue to teach me new things, each and every day. Your 
voices are important; don't ever stop speaking.

\section{References}

Alvermann, D. E. (2009). Sociocultural constructions of adolescence and young people's literacies. In R. Christenbury, R. Bomer \& P. Smagorinsky (Eds.), Handbook of adolescent literacy research (pp. 14-28). New York: Guilford Press.

Battiste, M. (2002). Indigenous knowledge and pedagogy in First Nations education: A literature review with recommendations. Ottawa: National Working Group on Education.

De Souza, L. M. T. M. (2015). Indigenous literacies in literacy studies. In J. Rowsell \& K. Pahl (Eds.), The Routledge handbook of literacy studies (pp. 157-168). London: Routledge.

Ginsburg, F. (2008). Rethinking the digital age. In P. Wilson \& M. Stewart (Eds.), Global Indigenous media: Cultures, poetics, \& politics (pp. 287-305). Durham, NC: Duke University Press.

Jacobs, Calvin. Personal communication.

Jacobs, C. (2016). Finding your voice: Cultural resurgence and power in political movement. In D. Reder \& L. M. Morra (Eds.), Learn, teach, challenge: Approaching Indigenous literatures (pp. 423-428). Waterloo: Wilfrid Laurier University Press.

Kovach, M. (2005). Emerging from the margins: Indigenous methodologies. In L. Brown \& S. Strega (Eds.), Research as resistance: Critical, Indigenous, and anti-oppressive approaches (pp. 19-36). Toronto: Canadian Scholars Press.

Kral, I. (2010). Plugged in: Remote Australian Indigenous youth and digital culture. Canberra, ACT: Centre for Aboriginal Economic Policy Research, Working paper number 69/2010. pp. 1-17.

Lavoie, C., Sarak, M., Mark, M., \& Jeniss, B. (2012). Multiliteracies pedagogy in language teaching: An example from an Innu community in Quebec. Canadian Journal of Native Education, 35(1), 194-224.

Mills, K. A., Davis-Warra, J., Sewell, M., \& Anderson, M. (2016). Indigenous ways with literacies: Transgenerational, multimodal, placed, and collective. Language \& Education, $30(1), 1-21$.

Mirra, N., Filipiak, D., \& Garcia, A. (2015). Revolutionizing inquiry in urban English classrooms: Pursuing voice and justice through youth participatory action research. English Journal, 105(2), 49-57.

Perry, K. H. (2012). What is literacy? A critical overview of sociocultural perspectives. Journal of Language \& Literacy Education, 8(1), 50-71.

The New London Group. (1996). A pedagogy of multiliteracies: Designing social futures. Harvard Educational Review, 66(1), 60-93. 